\title{
A Evidência das Essências e a Noção de Dado (Gegebenheit): a consciência como unidade e doação de sentido
}

\section{Rudinei Cogo Moor ${ }^{1}$}

Edmund Husserl nasceu no dia 8 de abril de 1859 em Prostějov, pequena localidade da Morávia (atual República Tcheca), quando esta ainda pertencia ao Império AustroHúngaro. Faleceu no dia 27 de abril de 1938, com 79 anos, em Friburgo, Alemanha. É responsável por ter deixado um legado filosófico e científico chamado fenomenologia. No início de sua formação acadêmica e intelectual, Husserl estudou e se especializou em matemática, concluindo seu doutorado com a tese "Contribuição à teoria do cálculo das variações" na Universidade de Viena. Nesta Universidade, Husserl assiste aos cursos de filosofia de Franz Brentano que influenciam radicalmente seu desenvolvimento filosófico. Por ser judeu, sofreu com a perseguição nazista.

Suas principais obras fenomenológicas são: Investigações Lógicas (1900-1901); A Ideia da Fenomenologia (1907); A Filosofia como Ciência Rigorosa (1911); Ideias para uma Fenomenologia Pura e uma Filosofia Fenomenológica I (1913); Lições para uma Fenomenologia da Consciência Interna do Tempo (1928); Lógica Formal e Transcendental (1929); Meditações Cartesianas (1931); Experiência e Juízo (1938), entre outras. Husserl deixou inúmeras páginas escritas (taquigrafadas) que estão preservadas nos arquivos Husserl em Lovaina, na Bélgica, cujas publicações saem com o nome de Husserliana.

A obra A ideia da fenomenologia é constituída por Cinco Lições, que foram pronunciadas por Husserl em Göttingen, do dia 26 de abril a 2 de maio de 1907. Segundo a introdução do editor alemão Walter Biemel, nessas Lições, Husserl apresenta as ideias que iriam determinar a fase de sua filosofia conhecida como fenomenologia transcendental. Ali ele expressa conceitos-chave que não mais o abandonaram, e que também nos ajudam a compreender seu empreendimento filosófico ulterior, tais como redução fenomenológica e constituição dos objetos na consciência.

\footnotetext{
${ }^{1}$ Doutorando em Filosofia pela Universidade Federal de Santa Maria (UFSM); Mestre em Filosofia (UFSM); Bacharel em Filosofia pela Sociedade Vicente Pallotti (SVP); tem seus estudo direcionados para a área da Filosofia, em especial na fenomenologia, estudando alguns temas e autores: subjetividade, ética, solipsismo, imparcialidade, intersubjetividade,Husserl, Waldenfels. E-mail: rudimoor@yahoo.com.br.
} 
Antes de adentrarmos nas cinco lições, é necessário entendermos alguns termos que o autor usa para distinguir suas posições. Primeiramente, quando Husserl fala de atitude (Einstellung) $^{2}$ natural e filosófica, não significa que a atitude filosófica seja um distanciamento da realidade e uma entrada no mundo das ideias ou representações. A atitude filosófica fenomenológica é uma crítica ao nosso posicionamento ingênuo no mundo - da atitude natural que temos em considerar que o natural - que envolve coisas empíricas, materiais, psicológicas, bem como o mundo e nós mesmos - é dado ou está no mundo independente da consciência. $\mathrm{Ou}$, até mesmo, achar que a consciência é um produto da mente ou de relações causais e fisioquímicas do cérebro. A atitude filosófica fenomenológica considera tudo o que está ai no mundo ou nas ideias como um dado (Gegebenheit) para a consciência, e a consciência em correlação intencional com esse dado. O mundo sem relação com a consciência é um mundo desprovido de sentido, e, sendo assim, sem razão de ser.

Husserl evita os termos "interior" e "exterior". Na substituição mais adequada destes, ele usa "imanente" e "transcendente". A consciência não é uma caixa ou um saco vazio e o conhecimento não é um produto cuja embalagem pode ser abstraída para "dentro" desta caixa. A consciência é um direcionamento intencional para algum dado intuitivo e, a intuição dá alguma coisa, segundo algum modo de consciência. Ao efetuar a $\varepsilon \pi \circ \chi \eta$ (epoché), que consiste em neutralizar o olhar ingênuo da atitude natural para o ver da atitude fenomenológica, tudo o que se doa para a consciência é visto através de um modo específico. Por exemplo: quando percebemos uma casa vermelha transcendente, vemos seus perfis (Abschattung) no modo de percepção transcendente. Quando fantasiamos que a casa poderia ser de outra cor, por exemplo, verde, fazemos assim ao modo imaginado. Depois, passado um tempo destas atividades conscientes, na memória recordamos, neste modo, as atividades anteriores e a casa. Para a fenomenologia não interessa a existência ou inexistência do dado, mas sim o modo como ele está dado para a consciência. O transcendente é perfilado, enquanto que o imanente é absoluto. No imanente estão incluídas nossas vivências, e um vivido nunca é perfilado. $\mathrm{O}$ absoluto significa a coisa mesma, o vivido, dado em uma unidade de sentido.

\section{As cinco lições da obra "A Ideia da Fenomenologia"}

\footnotetext{
${ }^{2}$ Alguns autores traduzem o termo alemão Einstellung como orientação.
} 
A primeira lição da obra "A ideia da fenomenologia" faz uma distinção entre duas atitudes pertinentes aos problemas e à possibilidade do conhecimento, que Husserl chama: "atitude espiritual natural" e "atitude espiritual filosófica". A primeira tem uma atitude despreocupada com relação à crítica do conhecimento, pois, nesta atitude, estamos inclinados para as coisas dadas no mundo. Diante de diversos objetos materiais manifestos no mundo, captamos várias espécies de ser, que podem ir além de meros objetos materiais, mas que, segundo cada grau de conhecimento, fazem referência à experiência direta que temos deles, quando formamos nossos juízos e exprimimos o que o mundo e seus objetos nos ofertam. Para a "atitude espiritual natural" é óbvia a possibilidade do conhecimento. Pelas concordâncias lógicas nas relações de conhecimentos, cremos que o mundo é tal e qual do modo que experimentamos, como um aí real do mundo natural e, mesmo quando sabemos que podemos nos enganar com aparências, o problema do conhecimento é resolvido de modo natural, tornando-se um fato natural e psicológico, vivenciado por seres orgânicos que conhecem. Em resumo, na "atitude espiritual natural" vamos diretamente ao objeto e seus encadeamentos empíricos possíveis de serem observados.

A "atitude espiritual filosófica" é definida como uma reflexão, em sua tarefa crítica e metodológica, sobre a possibilidade do conhecimento. Se na "atitude espiritual natural” o conhecimento é óbvio, na segunda atitude, ao se refletir sobre as relações entre conhecimento e objeto, surgem dificuldades e subitamente um mistério. Mas, quais são as dificuldades e como se dá este mistério? As dificuldades são pertinentes à possibilidade de um conhecimento tocante às próprias coisas, que por sua vez desembocam no mistério: como podemos estar certos de que o conhecimento pode atingir ou estar em correspondência com as coisas que existem em si? Nesta atitude, o conhecimento tem sua referência ao objeto, mas, correlato ao sujeito, sua possibilidade de ser conhecido por meio de uma vivência psíquica. Mas aqui se apresentam algumas dificuldades: a possibilidade de nos instalarmos no solipsismo, dizendo que o sujeito que conhece não vai além das conexões de sua vivência psicológica, referindo todo o conhecimento verdadeiro dado ao cognoscente como fenômeno subjetivo. Por outro lado, basear a possibilidade do conhecimento em uma constituição psicológica é baseá-la num fato, singular e particular, impossibilitando descrever um conhecimento verdadeiro e universal.

A “reflexão natural” pode nos levar ao relativismo sobre a essência do conhecimento, colocando interpretações fundamentalmente errôneas, em si mesmas contraditórias, pondo como fundamento algo que é contingente, como um fato natural. Husserl dá como exemplo 
a teoria da evolução, a qual coloca o desenvolvimento humano e seu intelecto (e todas as leis e formas lógicas) graças à seleção natural. Seguindo esta teoria, se as formas e leis lógicas, entendidas como fato psicológico, são provenientes do discurso da evolução, então elas poderão ser muito diferentes conforme as mudanças evolutivas no futuro, e com isso seremos incapazes de atingir a natureza das coisas mesmas, bem como a verdade, uma vez que somos produtos da evolução e ficaremos abandonados ao ceticismo ou ao relativismo. Ao contrário, para Husserl, as leis lógicas são verdades evidentes por si mesmas, que podem ser evidenciadas pela vivência psicológica, mas isso não significa que estas leis sejam produto ou criação das mesmas vivências, vide a validade absoluta do princípio de não-contradição. Portanto, a "reflexão natural" cai num contrassenso ao relativizar aquelas leis evidentes das quais ela mesma usa para comprovar suas teses relativistas. Somente uma "reflexão gnoseológica" pode realizar a separação da ciência natural e filosófica, evidenciando que "as ciências naturais do ser não são ciências definitivas do ser. É necessária uma ciência do ente em sentido absoluto" (Husserl, 1986, p. 46).

Para Husserl, a "tarefa" para esclarecer essas teses obscuras e contraditórias, e as disputas desse meio, é da teoria do conhecimento e da metafísica. Essa tarefa tem um lado negativo e o outro positivo. Do lado negativo, é uma tarefa crítica, pois visa “denunciar" os absurdos que a reflexão natural realiza com relação ao conhecimento, seu sentido, objeto, bem como "refutar" teorias que são céticas de modo aberto ou oculto, demonstrando seus contrassensos. Do lado positivo, através da essência do conhecimento, "solucionar" os problemas pertinentes à correlação entre conhecimento, sentido e objeto do conhecimento; e "evidenciar" o sentido da objetividade cognoscível em sua essência mesma. Para Husserl, se a metafísica tem por objetivo elucidar a essência do conhecimento e da objetividade cognitiva, então ela é fenomenologia do conhecimento e da objetividade cognitiva. Assim, a fenomenologia vai constituir um método filosófico e uma atitude intelectual filosófica, servindo como uma crítica das ciências naturais e seus conhecimentos, também como fundamento para a filosofia, fornecendo-lhe método novo que se contrapõe ao natural.

$\mathrm{Na}$ segunda lição aparece a pergunta: "Como se pode estabelecer a crítica do conhecimento?” (Ibid., p. 53). Husserl segue os passos de Descartes, e sua fenomenologia representa um contínuo-acabamento da tentativa cartesiana de fundamentação do conhecimento na base reflexiva do cogito e suas correlações. De modo análogo à dúvida cartesiana, a fenomenologia leva em consideração a metodologia da epoché, não pressupondo como previamente dado nenhum ser, conhecimento ou autoridade científica, 
tampouco os seus próprios saberes, para efetivar a sua crítica, até chegar no reconhecimento da evidência do conhecimento primeiro, absolutamente dado e indubitável em sua plena claridade. A própria dúvida cartesiana não consegue ser geral, pois se "tudo é duvidoso", então podemos "ter uma certeza", que a premissa anterior à conclusiva é verdadeira. Ademais, em cada caso em que se exerce a dúvida, é indubitavelmente evidente que se duvida de alguma coisa determinada. Para a fenomenologia, "toda a vivência e toda a vivência em geral, ao ser levada a cabo, pode fazer-se objeto de um puro ver e captar e, neste ver, é um dado absoluto. Está dada como um ente, como um isto-aqui (Dies-da), de cuja existência não tem sentido duvidar" (Ibid., p. 55-56). A aspiração da teoria do conhecimento é assinalar a esfera dos dados absolutos, o que toda vivência pode fornecer como dado.

Para Husserl, o que é enigmático sobre a possibilidade do conhecimento é a sua transcendência. A atitude científica, pré-científica e o conhecimento natural em geral têm a pretensão de conhecer cognoscitivamente objetos existentes, transcendentes que não lhe são imanentes, ou seja, estão exteriores aos atos cognoscitivos que se pressupõe a todo conhecer sobre algo. A transcendência descrita por Husserl aqui tem dois sentidos: a primeira pode indicar que o objeto do conhecimento não está contido no ato cognitivo como ingrediente, ou seja, ele não é um vivido real (reell) da consciência. Se a transcendência significa exterioridade que não está inclusa no ato de conhecer, a imanência ou "dado imanente" significa o que está inclusivamente contido, na qual ato de conhecimento e o objeto que ele intenta estão na cogitatio como vivência. O que resume este primeiro sentido é dado na pergunta: “como pode a vivência ir, por assim dizer, além de si mesma?” (Ibid., p. 60). O segundo sentido de transcendência designa "o dar-se absoluto e claro, a autopresentação em sentido absoluto (Ibid., p. 61). Quando algo dado transcendente é captado e visto imediatamente, há uma evidência que a consciência posiciona como um dado absoluto, vivenciado, que vai além do objeto transcendente "exterior". A pergunta que assinala aqui é: "como pode o conhecimento pôr como existente algo que nele não está direta e verdadeiramente dado?" (Idem).

A teoria do conhecimento precisa levar em consideração a correlação intencional entre conhecimento e o dado conhecido e o sentido geral que envolve essa relação. A ciência natural, por desconsiderar essa correlação e focar nos conteúdos naturais e transcendentes objetivantes, não deve ser relevante para a teoria do conhecimento, pois o problema "de como" (de como é possível o conhecimento e o conhecimento transcendente) jamais pode ser resolvido num saber transcendente, pois o que é empírico não pode ser explicado por ele 
mesmo. Assim, a crítica do conhecimento e sua elucidação não partirá da dedução ou indução de conhecimentos, mas o "ver intuitivo" que fundamentará a experiência e a sua possibilidade de ser conhecida.

Na terceira lição, Husserl insiste no enigma do conhecimento, que é, a saber, a possibilidade de sua transcendência, na qual não se leva em conta a realidade do transcendente. Como assim? Para a fenomenologia é mais evidente compreender como a percepção pode alcançar o imanente, pois, no caso da percepção imanente - a partir da percepção reflexiva e puramente imanente - apreendemos o dado absoluto diretamente no modo como intentamos o dado intuitivo e apreensivamente; ao passo que é difícil compreender como a percepção faz isso com o transcendente, ou como ele pode entrar no conhecimento, uma vez que o objeto transcendente se dá por perfis, nunca absolutamente, e o próprio fenômeno cognoscitivo é imanente e não algo transcendente. Por isso, a crítica do conhecimento não pode levar em conta o transcendente, mas questionar a sua possibilidade enquanto tal.

As cogitationes representam uma esfera de dados imanentes absolutos. Mas é preciso não confundir e evidência ontológica do ser da cogitatio com a particularidade da existência de qualquer cogitatio específica. Para evidenciar isso, Husserl efetua a "redução gnoseológica" que visa colocar em suspenso aquilo que é transcendente e, com isso, fica incluso os objetos transcendentes do mundo, o "eu empírico" e suas idiossincrasias. Aqui se faz necessário traçar a diferença entre "fenômeno psicológico" e "fenômeno puro". O primeiro contém o eu como pessoa e suas vivências empíricas particulares inseridas no tempo objetivo, e a ciência natural que trata disso é a psicologia. O fenômeno psicológico é colocado em suspenso pela redução gnoseológica. Mas o que resta depois disso? O fenômeno puro enquanto tal, dado pela "redução fenomenológica", que não oferece nenhum transcendente perfilado, mas o dado puro absoluto. A reflexão intuitiva voltada para a vivência psíquica revela o fenômeno puro de sua vida intencional, enquanto dado absoluto de sua essência puramente imanente.

Neste campo do "dado absoluto puramente imanente" é o ponto radical que a fenomenologia buscava, definindo-se como "ciência dos fenômenos puros" (Ibid., p. 73) e "doutrina da essência dos fenômenos cognitivos puros" (Ibid., p. 74). Mas aqui surgem algumas dificuldades e interrogações: algo de captável nos fenômenos puros ainda faz referência ao transcendente, sendo assim, individuais e concretos contingentes; portanto, como estabelecer uma ciência fenomenológica do universal e necessário? Como averiguar 
cientificamente e objetivamente o "campo" dos fenômenos puros, quando Husserl chama isso de um rio heraclitano de fenômenos? Como realizar juízos claros e cientificamente válidos?

O critério de certeza, assim como fora para Descartes, será partir da "percepção clara e distinta", mas captada e entendida no sentido mais puro. Portanto, a importância decisiva para a possibilidade da fenomenologia é de evidenciar que o conhecimento pode, em sua forma apreensível, “chegar ao absoluto dar-se em si não só objetos singulares, mas também universalidades, objetos universais e estados de coisas universais" (Ibid., p. 78-79). Desse modo, a fenomenologia, enquanto ciência e método, caracteriza-se por ser uma análise e investigação de essências a priori correlatas ao que é dado no âmbito intuitivo puro, da autopresentação absoluta, tendo por finalidade elucidar as possibilidades do conhecimento no sentido universal de essências.

A quarta lição investiga o campo das essências universais do conhecimento. Estas essências, pertencentes às vivências cognitivas imanentes, são intencionais, ou seja, visam algo ou fazem referência a uma objetividade. Agora é preciso analisar, com a abertura da redução fenomenológica e da autopresentação, as múltiplas espécies de fenômenos que constituem a fenomenologia do conhecimento, versando seus fundamentos e possibilidades.

A redução fenomenológica elabora a essência da estrutura fundamental e universal dos fenômenos. Por isso, nesta redução, não se está restritamente confinada à esfera da cogitatio, tampouco da imanência ingrediente que inclui particularidades das vivências, ou da esfera que percepciona, mas somente à esfera do dar-se em si mesmo, na autopresentação do que está dado exatamente no sentido em que é visado, em pura evidência. Esta evidência não pode ser confundida com o sentimento de evidência, que os teóricos empiristas do conhecimento usam para distinguir juízos evidentes dos juízos não-evidentes. Para a fenomenologia, evidência é a consciência que realmente vê, que apreende o que é dado direto e em si mesmo. Assim como temos a evidência do ser da cogitatio, também temos a evidência do universal, que surge na autopresentação como objetividades e estados de coisas universais em seu próprio sentido, dados em sentido rigoroso.

Como o universal pode ser dado em si mesmo numa evidência objetiva e intuitiva? Se a redução fenomenológica mostra que a intencionalidade ultrapassa o confinamento da cogitatio, então o universal a transcenderia (e também o conhecimento) e, mesmo assim, se autopresentaria no sentido de uma cogitatio? Então, uma coisa é o universal e outra a consciência desse universal? Para Husserl, o universal possui sua transcendência com 
relação ao conhecimento e, como ele não é particularidade alguma, não pode estar contido como ingrediente na consciência da universalidade. É preciso clarificar o fenômeno absoluto, a cogitatio reduzida de suas singularidades, no que se revela como autopresentação absoluta ao puro ver do dado absoluto e universal. Em suma, a conclusão que se segue é que, na análise e clarificação das essências e suas relações de conhecimento, em seus nexos teleológicos, a fenomenologia se depara com o que é de mais evidente, necessário e fundamental, qual seja: "o sentido", como ato de toda a razão em geral (epistemológica, valorativa e prática). Isso significa que, por mais diferentes e diversos que sejam os fenômenos e suas relações intencionais, há neles uma identificação universal unificada pelo sentido, conhecido intuitivamente no modo como se dão em si mesmos. Por exemplo, no vermelho que percebemos do objeto, há um sentido pressuposto que valida a própria objetividade do vermelho. Assim, o vermelho, como essência universal, só pode ser elucidado enquanto sentido, que lhe revela sua estrutura fenomênica e objetiva.

O sentido está implícito no ato da razão de conhecer no qual toda a objetividade está subordinada. No entanto, a razão aqui é conhecimento intuitivo, que reduz o entendimento, tendo em vista o que é visado puramente. Por isso, Husserl lembra: "o menos possível de entendimento, mas o mais possível de intuição pura" (Ibid., p. 92). A fenomenologia consiste em suspender todos os discursos, teorias racionais de significado, pré-conceitos etc. para o puro ver intuitivo, isto é, deixar que a evidência do dado absoluto se mostre em si mesmo para o ver da consciência.

A quinta e última lição trata sobre a constituição do sentido das objetividades que aparecem no fluxo da consciência, a partir da correlação entre atos cognoscitivos e suas objetividades, constituindo o campo fenomênico a ser investigado. Logo de início, podemos perguntar: qual a relação entre sentido e ser temporal e existente que é constituído como fenômeno? Como se dá esta constituição? Para apreender a essência dos fenômenos, seu sentido constituído universalmente, podemos nos ater somente na percepção? Para isso teríamos que observar todas as possibilidades em que, por exemplo, o vermelho se dá nos objetos e abstrair daí algum vermelho universal. Mas, não podemos ter a apreensão dessa essência numa fantasia clara, na qual o vermelho se dá para o ver intuitivo? Assim, do seu modo, também a recordação oferece diferentes formas de objetividade e do dar-se. Cabe à fenomenologia descrever e elucidar esses problemas.

Levando em conta a correlação que possibilita falarmos de conhecimento, em fenomenologia, Husserl faz uma distinção entre o "dar-se das essências" e a "apreensão das 
essências" (Wesenserfassung). No "dar-se das essências" podemos ver que o objeto se constitui no conhecimento, não apenas na percepção e retenção que lhe envolve, mas também na fantasia e rememoração em que se oferecem possibilidades intuitivas de serem captadas, visando intuitivamente nesse objeto um universal, do modo que se universaliza o que aparece, posicionando na sua aparição uma universalidade; assim também podem ser feitos com os atos cognoscitivos, que não estão presentes como ingredientes, mas que podem se oferecer à captação em sua essência universal. Neste "dar-se", os atos cognoscitivos revelam uma conexão correspondente entre si, exibindo uma unidade a partir dos vínculos teleológicos, que constituem a multiplicidade objetiva em sua estrutura lógica de apreensão.

$\mathrm{Na}$ “apreensão das essências" (Wesenserfassung) é irrelevante a posição de existência, colocando a percepção e a representação da fantasia em pé de igualdade, pois das mesmas se pode extrair e atingir a mesma essência. A "apreensão de essências" se "refere às espécies de dados psíquicos em sentido próprio, como juízo, afirmação, negação, percepção, raciocínio etc." (Ibid., p. 99). E isso vale também para universalidades, embora a apreensão de essências, plenamente evidente se constitua remetendo a uma intuição singular, sem, com isso, ser subsumida pela percepção singular, pois está colocada fora de jogo pela redução. Por exemplo, na mera fantasia, uma cor não é dada no mesmo sentido da sensação de uma cor. Mas, embora correlatas, uma coisa é a "cor fantasiada" e, outra, a "vivência do fantasiar esta cor". O que está dado para o sujeito, na sua vivência temporal é uma cogitatio agora existente, pois não pode negar estar vivenciando, enquanto apreende uma cor no ato da fantasia, "mas a cor em si mesma não é uma cor agora existente, não é uma cor sentida. Por outro lado, no entanto, ela está dada de certo modo, pois está diante dos meus olhos" (Ibid., p. 100).

A constituição da essência e sentido do conhecimento objetivo se configura na unidade que é apreendida através da multiplicidade de modos de dar-se dos objetos intencionais, bem como no modo de captá-los na correlação intencional da consciência. Enquanto fenômeno, todo o ser é constituído. Mas isso não significa que a consciência é igual a uma caixa ou um saco vazio, senão que por ela e ela mesma já está assim como um fenômeno dado para um eu, sem com isso ser objeto ou ter objetos como ingredientes "dentro" de si mesma.

A fenomenologia, enquanto ciência, vai procurar elucidar a essência do dar-se e do constituir-se dos diferentes modos de objetividade, não importando se esses modos apreendam objetos absurdos, invisíveis, impossíveis, contrassensos ou coisas ilógicas como 
um quadrado redondo. Desde que apareçam à consciência e se deem de certo modo evidente, a fenomenologia poderá elucidá-los de acordo como se dão em si mesmos. A grande questão, contudo, está na realização desta evidência, em estabelecer puramente o que está dado verdadeiramente e o que não está. "Exige-se a evidência de que o problema verdadeiramente importante é o da doação última do sentido por parte do conhecimento e, portanto, ao mesmo tempo, o da objetividade em geral, que só é o que é na sua correlação com o conhecimento possível" (Ibid., p. 107).

\section{Referências}

HUSSERL, E. A ideia da fenomenologia. Lisboa: Edições 70, 1986. 